Table 1 details respondents' reported competencies and training availability in 2010 curriculum skills.

Abstract P165 Table 1

\begin{tabular}{lccc}
\hline & $\begin{array}{l}\text { Competent } \\
(\%)\end{array}$ & $\begin{array}{l}\text { Not competent, } \\
\text { training } \\
\text { available (\%) }\end{array}$ & $\begin{array}{l}\text { Not competent, } \\
\text { training not } \\
\text { available (\%) }\end{array}$ \\
\hline Emergency contraception counselling & 100 & 0 & 0 \\
Referring to support organisations & 90 & 10 & 0 \\
Prescribing STI/HIV/Hep B prophylaxis & 90 & 10 & 0 \\
$\begin{array}{l}\text { SV history taking and risk } \\
\text { assessment in u-18s }\end{array}$ & 89 & 4 & 7 \\
$\begin{array}{l}\text { Forensic exam counselling/ } \\
\text { documenting injuries }\end{array}$ & 64 & 29 & 7 \\
$\begin{array}{l}\text { Documenting history/exam for } \\
\text { medico-legal report }\end{array}$ & 46 & 19 & 35 \\
\hline
\end{tabular}

Conclusions Wide variation exists in reported SV experience, training received and training availability, in the $28 \%$ of trainees responding. Regular accessible training is needed in identifying and managing patients disclosing SV.

\section{P166 INCREASING SCREENING FREQUENCY IN MEN WHO HAVE SEX WITH MEN (MSM): IMPACT OF EXPLICIT GUIDANCE ON RISK PROFILING ON UK SERVICE}

doi:10.1136/sextrans-2012-050601c.166

${ }^{1} \mathrm{~A}$ Baker, ${ }^{1} \mathrm{C}$ Fleury, ${ }^{2} \mathrm{E}$ Foley, ${ }^{2} \mathrm{~S}$ Samraj, ${ }^{2} \mathrm{D}$ Rowen, ${ }^{1,2} \mathrm{R}$ Patel. ${ }^{1}$ University of Southampton, Southampton, UK; ${ }^{2}$ Royal South Hants Hospital, Solent NHS trust, Southampton, UK

Background STI and HIV diagnoses are increasing among MSM. Mathematical modelling shows increasing screening frequency can reduce STI prevalence, especially targeting MSM engaging in risk behaviours. International guidelines from both the CDC and Australasian Society for HIV Medicine clearly define risk behaviours with adapted screening intervals - contrary to the UK where NICE guidance is vague.

Objectives To investigate impact of applying stricter international screening guidelines for MSM, on service workload and earlier STI diagnosis in a UK level 3 service [L-3S].

Methods A validated risk questionnaire distributed to MSM attending a large provincial L-3S over a 3-month period explored their actual screening frequency, STI diagnoses and risk behaviours in the prior 12 months. Australian screening guidelines were applied to the data to identify MSM needing more frequent screening. Projections to the larger MSM population attending over 12 months were modelled, based on the demographics of the respondents.

Results 126/357 completed the questionnaire, 89 were identifiable. There was no statistically significant difference between STI rates $(p=0.18)$ and HIV diagnoses $(p=0.62)$ between identifiable questionnaire respondents and other MSM clinic attendees. Demographic analysis showed the sample group was representative of the larger cohort. In 2011, applying Australasian Society for HIV Medicine risk profiling for the 793 MSM who attended the unit, $26 \%$ would require one additional 6-monthly attendance for HIV screening, while $6 \%$ would require two visits. Additional STI screening visits would be needed by $25 \%$ (1 visit) and 10\% (2 visits). $29 \%$ of STI diagnoses were in infrequent attendees.

Conclusions Stricter UK screening guidelines for MSM defining and weighting risk behaviours explicitly in line with other international guidelines, would increase L-3S MSM visits by $30 \%$ and potentially diagnose a large proportion of disease earlier. In light of the results UK guidelines may benefit from review.
MANAGEMENT CHALLENGES OF A TRIFECTA (HIV, HEPATITIS C AND SYPHILIS TRI-INFECTION) AND AN UPDATE ON HIV/HCV CO-INFECTION

doi:10.1136/sextrans-2012-050601c.167

\section{Khaw.* Royal Adelaide Hospital, Adelaide, South Australia, Australia}

This complex case is of an ageing HIV positive patient, who had been a management challenge to a multidisciplinary team over the past decade in Adelaide, South Australia. He had various comorbidities and had developed various other infections, mostly sexually acquired, complicating his management. The patient was diagnosed as HIV positive in 1985 and commenced on HAART in 1989 . He relocated to Adelaide in 2002. His major issues at that time were sexual dysfunction and bipolar affective disorder. On routine screening mid 2005, his CD4 count had dropped. Liver function tests were abnormal with raised GGT, ALT and AST. Subsequently, he was found to be Hepatitis C positive (Genotype 3). He adamantly denied intravenous drug use but had unprotected anal intercourse with other men. He also had a Prince Albert ring inserted. The hepatitis C infection was apparently acquired sexually. He proceeded to have multiple sexual partners interstate and overseas. On return to Adelaide at the end of 2005, he was found to be syphilis EIA positive, RPR 1:32 and FTA IgG positive. He was treated with benzathine penicillin. Management of his hepatitis $\mathrm{C}$ initially involved changes to his HAART over the next 2 years before he finally decided to commence interferon and ribavarin therapy for his Hepatitis C co-infection. He was on treatment for 6 months, with close monitoring by the team psychiatrist in view of his psychiatric comorbidities. To date, he has maintained sustained virological response. An overview of $\mathrm{HIV} / \mathrm{Hepatitis} \mathrm{C}$ co-infection from recent literature review will also be presented.

\section{Clinical case reports}

\section{P168 ACUTE GENERALISED EXANTHEMATOUS PUSTULOSIS INDUCED BY PNEUMOCYSTIS CARINII PNEUMONIA (PCP) PROPHYLAXIS WITH DAPSONE}

doi:10.1136/sextrans-2012-050601c.168

${ }^{1} \mathrm{~A}$ Vas, ${ }^{*}{ }^{2} \mathrm{P}$ M Laws, ${ }^{2} \mathrm{~A}$ M Marsland, ${ }^{1} 0$ McQuillan. ${ }^{1}$ Manchester Centre for Sexual Health and HIV, Manchester, UK; ${ }^{2}$ Department of Dermatology, Salford Royal Hospital, Manchester, UK

Background Acute generalised exanthematous pustulosis (AGEP) is a severe cutaneous adverse reaction. Most cases are drug related, however the condition has been associated with viral infections.

Objective AGEP in the setting of HIV is uncommon. We report a case of AGEP induced by PCP prophylaxis with dapsone.

Results A 34-year-old HIV-infected Nigerian woman was admitted to hospital with a 2 -week history of a progressing pustular skin rash. CD4 count 1 month prior to admission was 176 cells $/ \mathrm{mm}^{3}$ and she had not been taking antiretrovirals since 2008. Three weeks prior to presentation she had commenced Dapsone for PCP prophylaxis. Admission to hospital revealed a fever of $40^{\circ} \mathrm{C}$, tachycardia, hypotension and a widespread erythematous papular eruption with overlying pustules. Laboratory investigations revealed; haemoglobin $7.6 \mathrm{~g} / \mathrm{dl}$, raised oeosinophils of $0.67 \times 109 / 1$, C reactive protein $144 \mathrm{mg} / \mathrm{l}$ and Direct Coombs test was positive. A venous metheamoglobin level was raised at $3.5 \%$ and chest radiography revealed subtle consolidation at the left base. Broad spectrum antibiotics and fluids were initiated and Dapsone was withdrawn. Dermatology review raised the clinical suspicion of drug rash with oeosinophilia and systemic symptoms (DRESS) or AGEP. Skin biopsy supported the clinical diagnosis of AGEP. She remained systemically unwell 